\title{
Resistance to $\beta$-lactams of human and veterinary Salmonella isolates in Egypt and Algeria
}

\author{
Abdelhakim Aouf ${ }^{1,2}$, Yamina Messai ${ }^{1}$, Mohammed S. Salama ${ }^{3}$, Hala M. Aboushady ${ }^{2}$, \\ Mervat G. El-Anany ${ }^{4}$, Souhila Alouache ${ }^{1}$ and Rabah Bakour ${ }^{1 *}$ \\ ${ }^{1}$ Laboratory of Cellular and Molecular Biology, Faculty of Biological Sciences, University of Science and Technology \\ Houari Boumediene, Algiers, Algeria. \\ ${ }^{2}$ Microbiology Laboratory, Faculty of Science, Ain Shams University, Cairo, Egypt. \\ ${ }^{3}$ Molecular Biology Laboratory, Faculty of Science, Ain Shams University, Cairo, Egypt. \\ ${ }^{4}$ Microbiology Laboratory, Kasr Alainy Hospital, Cairo, Egypt. \\ Accepted 28 March, 2011
}

\begin{abstract}
Seventy six non-typhoid Salmonella were isolated from both human and poultry in Egypt and Algeria and tested for their antibiotics resistance. The incidence of multiple antibiotics resistance was high. To study $\beta$-lactams resistance mechanisms, double disk synergy test (DDST) with and without cloxacilline was used, results revealed the production of extended spectrum $\beta$-lactamases (ESBLs) and cephalosporinase in seven and one human Egyptian isolates, respectively. The seven ESBL isolates were identified as Salmonella enterica serotype Poona and their molecular typing by ERIC-PCR revealed unrelated genetic patterns, indicating that these isolates are not clonal. The Cephalosporinase-ESBL- producing isolate was identified as $S$. enterica serotype Hadar. Polymerase chain reaction (PCR) with specific primers showed the presence of $b_{1} a_{T E M}$ and bla $a_{S H V}$ genes, respectively, in all and four ESBL producers, and $b / a_{A m p c}$ gene was detected in cephalosporinaseproducing isolate. Genetic transfer by conjugation and plasmid profiles analysis showed that these genes and their resistance markers were transferable in association with plasmids of $60 \mathrm{~kb}$ for ESBLs and 64 and $3.2 \mathrm{~kb}$ for AmpC cephalosporinase.
\end{abstract}

Key words: Non-typhoid Salmonella, extended spectrum $\beta$-lactamases, cephalosporinase, Egypt, Algeria.

\section{INTRODUCTION}

Salmonella are widely distributed in nature and the most common reservoir of these bacteria is the gut of vertebrates. They are the major cause of food-born bacterial diseases. They cause a wide range of clinical illness: enteric fever, gastroenteritis, and bacteraemia, particularly in infants and in immunocompromised patients (Fluit, 2005). The incidence of salmonellosis is rising in the most of countries, which become one of the public health problems. Along with this incidence, increasing rates of antibiotic resistance have been

*Corresponding author. E-mail: rbakour@yahoo.fr. Tel: 0021321247913 . Fax: 0021321247217. reported in various regions. Therefore the effectiveness of antimicrobial chemotherapy is being eroded, and multidrug resistance clones were disseminated worldwide; in 2004, Salmonella resistant to extended spectrum cephalosporines (ESCs) were identified in 43 countries (Edelstein et al., 2004; Arlet et al., 2006). $\beta$ lactams constitute the most important antibiotic family in therapeutic, because of their efficiency and relative low toxicity. ESCs are currently the agents of choice for such chemotherapy especially for infants and neonates, for whom the use of fluoroquinolones is not yet approved (Bouallègue et al., 2005; Wilke et al., 2005). The selective pressure created by the use of ESCs has been described as one of the most important factors in the emergence of plasmid mediated extended spectrum 
$\beta$-lactamases (ESBLs) and Amp-C type cephalosporinases (Winokour et al., 2001; Miriago et al., 2004). ESBLs are clavulanate-susceptible enzymes capable of hydrolyzing oxyimino-cephalosporins and monobactams but not cephamycins and carbapenems. They belong to the Ambler class $A$ and functional group 2 be of the Bush-Jacoby-Meideros classification (Ambler, 1980; Bush et al., 1995; Bush and Jacoby, 2010). ESBLs are the first cause of resistance of Enterobacteriaceae to extended spectrum $\beta$-lactams that hamper infections treatment. They have evolved mainly from the old $\beta$ lactamases TEM-1 or TEM-2, and SHV-1 by various amino acid substitutions around active site. Reports described the emergence of ESBLs classes, such as PER, VEB, GES,TLA-1, IBC and CTX-M. The CTX-M $\beta$ lactamases are rapidly increasing, they were recognized in outbreaks in many parts of the world (Bonnet, 2004; Pitout et al., 2005; Hawkey and Jones, 2009). AmpC-type cephalosporinases (chromosomal or plasmid encoded), representing class C $\beta$-lactamases, are clinically significant as these confer resistance to cephalosporins in the oxyimino group, $7 \alpha$ methoxy cephalosporins, and not inhibited by $\beta$-lactams inhibitors (Bush et al., 1995; Bush and Jacoby, 2010). Dissemination of specific clones or/and epidemic resistance plasmids in community and hospitals is the main cause of the widespread of ESBLs and cephalosporinases (Messai et al., 2008; labadene et al., 2009).

With the importance of the bacterium Salmonella as pathogen of human and animals, and very few resistance data published in Algeria and Egypt, the aim of this study is the determination of susceptibility to 26 antibiotics of clinical and veterinary importance of 76 Salmonella and screening for the ESBLs and AmpC type cephalosporinases.

\section{MATERIALS AND METHODS}

\section{Bacterial isolates}

A total of 76 non-typhoid Salmonella were isolated from human and veterinary pathological specimens. Human isolates were collected from microbiology laboratories of two university hospitals in CairoEgypt (Demerdash-Ain Shams university and Kasr-Alainy-Cairo university), and two university hospitals in Algiers-Algeria (Mustapha-Bacha and Hadi Flici- Algiers university). Avian isolates were collected from microbiology laboratories of veterinary collegeCairo and Veterinary school- Algiers. The isolates were identified by the API 20E system, (Biomerieux, Marcy l'Etoile, France), PCR using invA primers: invA/F (5'GTGAAATTATCGCCACGTTCGGGCAA-3') and invA/R (5'TCATCGCACCGTCAAAGGAACC-3') (Rahn et al., 1992) and serotyping.

\section{Antimicrobial susceptibility and synergy testing}

Antibiotic susceptibility was done on Muller-Hinton agar plates with the disk diffusion method and interpreted according to CA-SFM guidelines (2009). Antibiotic disks were purchased from Bio-Rad.
Escherichia coli ATCC 25922 was used as a control strain. Betalactamases production was revealed by iodometric method (Courvalin et al., 1985). Extended-spectrum beta-lactamases and cephalosporinases production was screened by the Double-Disk Synergy Test (DDST) with and without cloxacilline $(250 \mathrm{mg} / \mathrm{L})$ (Jarlier et al., 1988).

\section{Plasmid analysis}

Plasmid DNA was extracted by alcalin-lysis method as previously described (Kado and Liu, 1981), and analysed by electrophoresis on $0.7 \%$ agarose gel in presence of the following reference plasmids : from $E$. coli V517 harboring 8 plasmids: $54.4,7.3,5.6$, 5.2, 4, 3, 2.7 and 2.1 kb; pBR322: 4.36 kb; RP4: 60 kb.

\section{Characterization of ESBL- and cephalosporinase-encoding genes}

DNA was obtained by heating a suspension of colonies in $50 \mu \mathrm{l}$ of water to $95^{\circ} \mathrm{C}$ for $10 \mathrm{~min}$. The DNA-containing supernatant was then used as a template in specific PCR for the detection of blaTEM, blasHv, blactX-M, bla $a_{\mathrm{GES}-1}$, blapER-1 and bla $a_{\mathrm{AmpC}}$. PCR amplification was performed by using the following primers : TEM/F (5'ATGAGTATTCAACATTTCCG-3') and TEM/R (5' CCAATGCTTAATCAGTGAGG-3'); SHV/F: (5'TTATCTCCCTGTTAGCCACC-3') and SHV/R: (5'GAGCCCGTTTTATGCACCCA-3'); GGTTAAAAAATCACTGCGTC-3') TTGGTGACGATTTTAGCCGC-3'); ATCGGCTTCATTCACGCAC-3') CTATTTGTCCGTGCTCAGG-3'); AATTTGGGCTTAGGGCAGAA-3') ATGAATGTCATTATAAAAGC-3'); ATCAAAACTGGCAGCCG-3') ( Cycling conditions were as following: initial denaturation at $95^{\circ} \mathrm{C}$ for 5 min followed by 35 cycles of denaturation at $94^{\circ} \mathrm{C}$ for $30 \mathrm{~s}$, annealing at $50^{\circ} \mathrm{C}$ (SHV), $53^{\circ} \mathrm{C}$ (TEM), $55^{\circ} \mathrm{C}$ (CTX-M and GES), $42^{\circ} \mathrm{C}$ (PER) and $65^{\circ} \mathrm{C}$ $(\mathrm{AmpC})$ for $1 \mathrm{~min}$, and elongation at $72^{\circ} \mathrm{C}$ for $1 \mathrm{~min}$. The final elongation step was extended to $10 \mathrm{~min}$ at $72^{\circ} \mathrm{C}$. The PCR products were separated on $1.5 \%$ agarose gels. Bands were visualized under ultraviolet light after being stained with ethidium bromide and photographed. Expected sizes of TEM, SHV and AmpC PCR products were, respectively, 310, 858 and 510 bp (Gebreyes and Altier, 2002; Yates et al., 2003; Kim et al., 2004; Poirel and Nordmann, 2005; Messai et al., 2006; labadene et al., 2008).

\section{Conjugation experiments}

Mating experiments were performed as previously described (Bakour et al., 1983) with E. coli BM21 (Nalidixic acid resistant) as a recipient. Selective agents were used at the following concentrations: $50 \mu \mathrm{g} / \mathrm{ml}$ for nalidixic acid and amoxicillin, and 2 $\mu \mathrm{g} / \mathrm{ml}$ for cefotaxime. Transconjugants were subjected to antibiotics susceptibility, DDST and PCR.

\section{Enterobacterial repetitive consensus PCR (ERIC-PCR)}

The epidemiological relationships between ESBL-producing $S$. enterica serotype Poona isolates were analysed by ERIC-PCR using primer ERIC-2 (5'-AAGTAAGTGACTGGGGTGACGC-3') (Decré et al., 2004). Cycling conditions were as follows: 3 min at $95^{\circ} \mathrm{C}, 40$ cycles of $30 \mathrm{~s}$ at $92^{\circ} \mathrm{C}, 1 \mathrm{~min}$ at $52^{\circ} \mathrm{C}$ and $8 \mathrm{~min}$ at $72^{\circ} \mathrm{C}$, and final extension of $16 \mathrm{~min}$ at $72^{\circ} \mathrm{C}$. Fingerprints were visually 
Table 1. Percentage of resistance to antibiotics according to country and source of isolation.

\begin{tabular}{|c|c|c|c|c|}
\hline \multirow{3}{*}{ Antibiotic discs } & \multicolumn{4}{|c|}{ Percentage of resistance (\%) } \\
\hline & \multicolumn{2}{|c|}{ Human } & \multicolumn{2}{|c|}{ Poultry } \\
\hline & Egypt, $\mathrm{n}=\mathbf{2 0}$ & Algeria, $\mathrm{n}=\mathbf{2 0}$ & Egypt, $\mathrm{n}=\mathbf{2 0}$ & Algeria, $n=16$ \\
\hline AMX $(25 \mu \mathrm{g})$ & 70 & 40 & 0 & 31.25 \\
\hline AMC $(20+10 \mu \mathrm{g})$ & 50 & 0 & 0 & 25 \\
\hline ATM $(30 \mu \mathrm{g})$ & 40 & 0 & 0 & 6.25 \\
\hline CRO $(30 \mu \mathrm{g})$ & 40 & 0 & 0 & 0 \\
\hline CAZ $(30 \mu \mathrm{g})$ & 40 & 0 & 0 & 0 \\
\hline FOX $(30 \mu \mathrm{g})$ & 50 & 0 & 0 & 18.75 \\
\hline CXM $(30 \mu \mathrm{g})$ & 40 & 0 & 0 & 12.5 \\
\hline СTX $(30 \mu \mathrm{g})$ & 40 & 0 & 0 & 0 \\
\hline TIC $(75 \mu \mathrm{g})$ & 70 & 40 & 0 & 12.5 \\
\hline TCC $(75+10 \mu \mathrm{g})$ & 55 & 10 & 0 & 0 \\
\hline MEC $(10 \mu \mathrm{g})$ & 70 & 5 & 15 & 6.25 \\
\hline IMP $(10 \mu \mathrm{g})$ & 0 & 0 & 0 & 0 \\
\hline$M Z(75 \mu \mathrm{g})$ & 60 & 20 & 0 & 6.25 \\
\hline CF $(30 \mu \mathrm{g})$ & 60 & 5 & 0 & 25 \\
\hline TZP $(75+10 \mu \mathrm{g})$ & 0 & 0 & 0 & 0 \\
\hline PIP $(75 \mu \mathrm{g})$ & 65 & 10 & 0 & 12.5 \\
\hline TE (30 IU) & 85 & 85 & 85 & 100 \\
\hline AN $(30 \mu \mathrm{g})$ & 50 & 0 & 0 & 6.25 \\
\hline$S(10)$ & 70 & 35 & 55 & 68.75 \\
\hline GM $(15 \mu \mathrm{g})$ & 70 & 0 & 0 & 0 \\
\hline $\mathrm{K}(30 \mu \mathrm{g})$ & 55 & 5 & 50 & 0 \\
\hline CIP $(5 \mu \mathrm{g})$ & 0 & 0 & 0 & 0 \\
\hline NA $(30 \mu \mathrm{g})$ & 35 & 35 & 55 & 18.75 \\
\hline NOR $(5 \mu \mathrm{g})$ & 0 & 0 & 10 & 0 \\
\hline $\mathrm{C}(30 \mu \mathrm{g})$ & 20 & 15 & 25 & 0 \\
\hline $\operatorname{SXT}(1.25+23.75 \mu \mathrm{g})$ & 5 & 5 & 30 & 18.75 \\
\hline
\end{tabular}

AMX : Amoxicillin, AMC : Amoxicillin/clavulanic acid, ATM : Aztreonam, CRO : Ceftriaxone, CAZ : Ceftazidime, FOX : Cefoxitin, CXM : Cefuroxime, CTX : Cefotaxime, TCC : Ticarcillin/ clavulanic acid, TIC : Ticarcillin, MEC : Mecillinam, IMP : Imipinem, MZ Mezlocilline, CF : Cefalotin, PIP : Piperacillin,TZP : Piperacillin/tazobactam, , TE : Tetracycline, AN : Amikacin, S : Streptomycin, GM : Gentamicin, K : Kanamycin, CIP : Ciprofloxacin, NA : Nalidixic acid, NOR: Norfloxacin, C : Chloramphenicol, SXT : Trimethoprime-sulphamethaxazole.

compared and the patterns differing by at least one amplification band were classified different.

\section{RESULTS}

Results showed that isolates were globally multidrugresistant (MDR); however, the resistance gradually declined or no resistance was observed for third generation cephalosporins, imipinem, piperacillin/ tazobactam, fluoroquinolones, Trimethoprimesulphamethoxazole, and chloramphenicol (Table 1). Notable findings are the resistance of eight (40\%) human Egyptian isolates to all tested third generation cephalosporins (3GCs) and to non-beta-lactams antibiotics as aminoglycosides, chloramphenicol, tetracycline, trimethoprime-sulphamethoxazole and nalidixic acid. The multiple antibiotic resistance patterns includes till fifteen antibiotics (Table 2).

The beta-lactamases production have concerned 70 , 40, 31, 5 and $0 \%$ of human Egyptian, human Algerian, poultry Algerian and poultry Egyptian isolates, respectively. A synergy between clavulanic acid and third and fourth generation cephalosporins characterizes seven 3GCs resistant human Egyptian isolates, this augurs the ESBL production, and all of these isolates were identified as $S$. enterica serotype Poona. The molecular typing revealed that these isolates have different ERIC-PCR patterns, indicating clearly heterogeneity in genetic profiles. For the remaining 3GCs resistant human Egyptian isolate, the supplementation with cloxacillin restored the activity of cefotaxime and 
Table 2. Resistance phenotypes, plasmids and $\beta$-lactamases of extended-spectrum cephalosporins resistant isolates

\begin{tabular}{|c|c|c|c|c|c|c|}
\hline \multirow{2}{*}{ Isolates } & \multirow{2}{*}{ Resistance pattern } & \multirow{2}{*}{$\begin{array}{l}\text { Plasmids } \\
\text { content (kb) }\end{array}$} & \multirow{2}{*}{$\beta$-lactamases } & \multicolumn{3}{|c|}{ Transfer (transconjugants) } \\
\hline & & & & $\beta$-lactamase & Transferred resistance & Plasmids \\
\hline S. poona S3 & $\begin{array}{l}\text { AMC CRO CAZ FOX CXM CTX AMX TIC } \\
\text { AMP MZ TE AN S GN K }\end{array}$ & $60-3.4-2.5$ & TEM, SHV & TEM, SHV & $\begin{array}{l}\text { AMC CRO CAZ CXM CTX AMX TIC } \\
\text { AMP MZ AN S GN K }\end{array}$ & 60 \\
\hline S. Hadar S4 & $\begin{array}{l}\text { AMC CRO CAZ FOX CXM CTX AMX TIC } \\
\text { AMP MZ TE AN S GN K NA }\end{array}$ & $64-8-4.4-3.2$ & AmpC, TEM, & AmpC, TEM, & $\begin{array}{l}\text { AMC CRO CAZ FOX CXM CTX } \\
\text { AMX TIC AMP MZ }{ }^{(I)} \mathrm{S}\end{array}$ & $64-3.2$ \\
\hline S. Poona S6 & $\begin{array}{l}\text { AMC CRO CAZ FOX CXM CTX AMX TIC } \\
\text { AMP MZ TE AN S GN K }\end{array}$ & $60-3.4-2.5$ & TEM & TEM & $\begin{array}{l}\text { AMC CRO CXM CTX AMX TIC AMP } \\
\text { MZ AN K }\end{array}$ & 60 \\
\hline S. poona S9 & $\begin{array}{l}\text { AMC CRO CAZ FOX CXM CTX AMX TIC } \\
\text { AMP MZ TE AN S GN K }\end{array}$ & $60-3.4-2.5$ & TEM & TEM & $\begin{array}{l}\text { AMC CRO CAZ CXM CTX AMX TIC } \\
\text { AMP MZ AN K }\end{array}$ & 60 \\
\hline S. poona S11 & $\begin{array}{l}\text { AMC CRO CAZ FOX CXM CTX AMX TIC } \\
\text { AMP MZ TE AN S GN K NA }\end{array}$ & $60-3.4-2.5$ & TEM, SHV & TEM, SHV & $\begin{array}{l}\text { AMC }^{(I)} \text { CRO CAZ CXM CTX } \\
\text { TIC AMP MZ AN K }\end{array}$ & 60 \\
\hline S. poona S12 & $\begin{array}{l}\text { AMC CRO CAZ FOX CXM CTX AMX TIC } \\
\text { AMP MZ TE AN S GN K C }\end{array}$ & $60-3.4-2.5$ & TEM & TEM & $\begin{array}{l}\text { AMC }{ }^{(I)} \text { CRO CAZ CXM CTX AMX } \\
\text { TIC AMP MZ AN K }\end{array}$ & 60 \\
\hline S. poona S13 & $\begin{array}{l}\text { AMC CRO CAZ FOX CXM CTX AMX TIC } \\
\text { AMP MZ TE AN S GN K }\end{array}$ & $\begin{array}{l}60-5.2-3.4- \\
2.5\end{array}$ & TEM, SHV & TEM, SHV & $\begin{array}{l}\text { AMC }{ }^{(I)} \text { CRO CAZ CXM CTX AMX } \\
\text { TIC AMP MZ AN K }\end{array}$ & 60 \\
\hline S. poona S15 & $\begin{array}{l}\text { AMC CRO CAZ FOX CXM CTX AMX TIC } \\
\text { AMP MZ TE AN S GN K }\end{array}$ & $60-3.4-2.5$ & TEM, SHV & TEM, SHV & $\begin{array}{l}\text { AMC (I) CRO CAZ CXM CTX AMX } \\
\text { TIC AMP MZ AN K }\end{array}$ & 60 \\
\hline
\end{tabular}

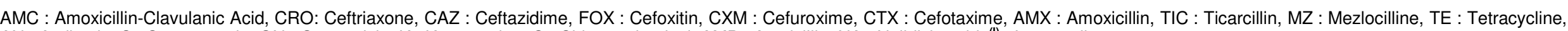
AN : Amikacin, S : Streptomycin, GN : Gentamicin, K : Kanamycine, C : Chloramphenicol, AMP : Ampicillin, NA : Nalidixic acid, ${ }^{(1)}$ : Intermediate.

increased that of cefepim; this is indicative for cephalosporinase production by this isolate, which was identified as $S$. enterica serotype Hadar.

PCR amplification performed on the 7 ESBL and one cephalosporinase producing Egyptian human isolates revealed the presence of blaTEM and bla $a_{\mathrm{SHV}}$ in four isolates bla
blateM and bla $a_{A M P C}$ in one isolate. The plasmid profile analysis of selected MDR isolates from human and poultry in both countries, revealed the presence of more than two plasmids in most isolates. The number and size of plasmids in MDR human Egyptian isolates were higher than those in other isolates. Six of ESBL Egyptian human isolates have the same plasmid profile (3 plasmids) (Table 2). Mating assays carried out on ESBL and cephalosporinase isolates allowed the transfer of ESBL and cephalosporinase phenotypes to recipient $E$. coli BM21 in association with plasmid of 60,64 and $3.2 \mathrm{~kb}$ respectively (Figure $1 \mathrm{~A}$ and $\mathrm{B}$ ). 


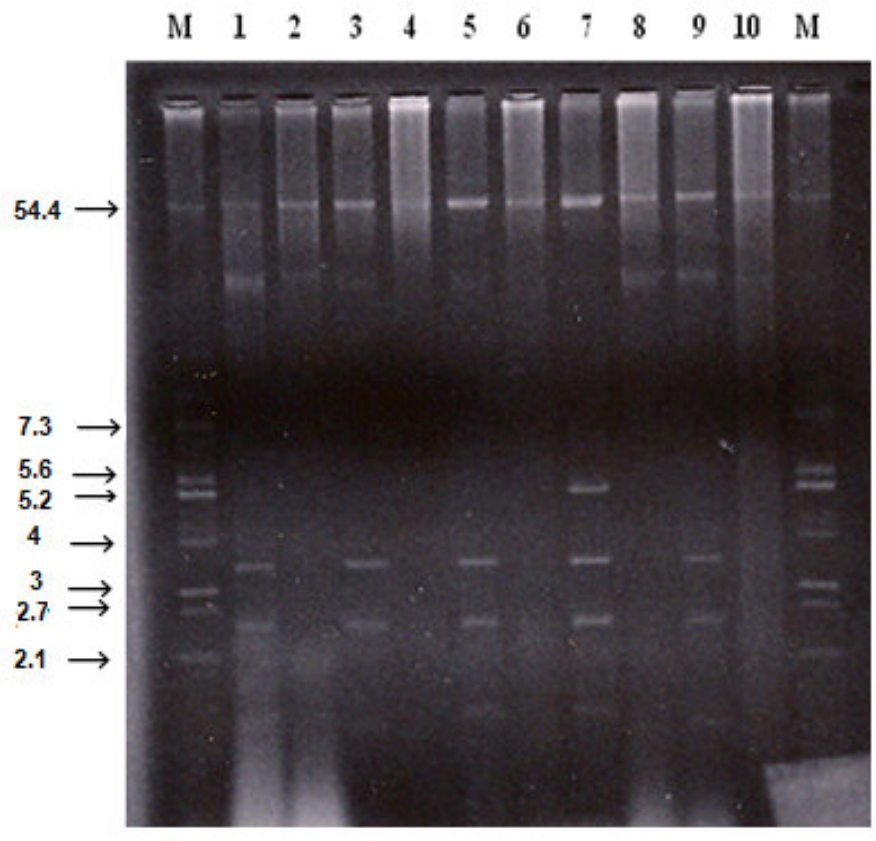

A

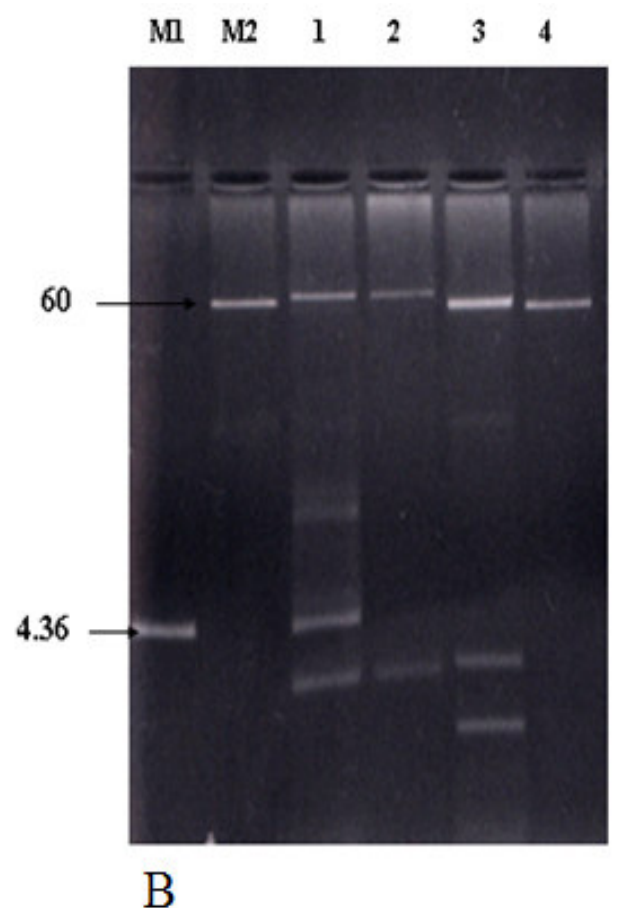

Figure 1. Agarose gel electrophoresis of the plasmidic extract of ESBL and cephalosporinase Salmonella from human in Egypt and their transconjugants. (A) Lane 1-2: Salmonella poona S9 and its transconjugant; Lane 3-4: Salmonella poona S11 and its transconjugant; Lane 5-6: Salmonella poona S12 and its transconjugant; Lane 7-8: Salmonella poona S13 and its transconjugant; Lane 9-10: Salmonella poona S15 and its transconjugant. M: Standard plasmids from E. coli V517 harboring 8 plasmids: 54.4, 7.3, 5.6, 5.2, 4, 3, 2.7 and $2.1 \mathrm{~kb}$. (B) Lane 1-2 : Salmonella Hadar S4 and its transconjugant; Lane 3-4 Salmonella poona S6 and its transconjugant. M1: RP4 (60kb), M2 : pBR322 (4.36 kb).

\section{DISCUSSION}

The high rate of resistance to tetracycline, streptomycin and nalidixic acid is mainly due to the early introduction of these antibiotics in veterinary and human medicine. The high rate of resistance to all tested ESCs of human Egyptian isolates constitutes a serious public health problem, especially for neonates and childrens under 7 years, since ESCs are the antibiotics of choice for invasive Salmonella infections in children (Hohmann, 2001; Bouallègue et al., 2005). The emergence of ESCsresistant Salmonella in Egypt has been reported many times (Bouchillon et al., 2004; AbdelGhani et al., 2010). The sensitivity of human Algerian isolates to 3GCs is probably due to the fact that these antibiotics are not available in the community and not used extensively in hospital practice. The most active drugs against our isolates were imipinem, piperacillin/tazobactam (TZP) and fluoroquinolones. The resistance phenotypes of nontyphoid Salmonella noted in this study may be considered alarming, because this bacterium was reported as sensitive. This result is consistent with the emergence of multidrug-resistance and ESBL production within nontyphoid Salmonella (Miriago et al., 2002, 2004; Chen et al., 2010). This high frequency of resistance might be due to the easily acquisition of resistance, or to the exposition of natural reservoirs (human and animal gastrointestinal tracts) to large amounts of antibiotics. The second hypothesis is more probable for this genus when we see that most multi-drug resistant isolates in our study were recovered from neonates, and the evolution of resistance in Salmonella was initially more moderate compared to those of other species of Enterobacteriaceae such as $E$. coli and Klebsiella (Bradford, 2001a; Yates and Amyes, 2005).

It has been reported worldwide that most non-typhoid Salmonella that resist to ESCs had been resulted from human (Gaillot et al., 1997; Banajah et al., 2001; Chande et al., 2002; Miriago et al., 2004; Chen et al., 2010). However, in certain countries, such as USA and Canada, resistance to ESCs is derived from both human and animal (Winokour et al., 2001).

Despite their genetic differences, six ESBL isolates have the same plasmid profile, this suggest that they emerged under the same selective pressure which promotes genetic exchanges between bacteria in hospital environments. The exchange of resistance plasmids between members of Enterobacteriaceae will severely limit the treatment options of infections caused by these microorganisms, which are responsible for nearly half of all infections (Fluit, 2005). Many ESBLs-mediated plasmids also contain virulence genes or regulate their 
expression; this confers survival advantage in an unfavorable drug environment and constitutes a new tool in the bacterial evolution (Guerra et al., 2002; Martinez and Baquero, 2002; Chu and Chiu, 2006).

Amplification by PCR showed that ESBLs were bla $a_{\mathrm{TEM}}$ or bla SHV $_{\mathrm{SH}}$ types, these enzymes have been recorded widely in Enterobacteriaceae worldwide, often in association with resistance to other antimicrobial classes like aminoglycosides. ESBLs TEM and SHV types have been described in Salmonella in Egypt and worldwide, but currently trend is the emergence of ESBL CTX-M type in this genus.

(Livermore, 2004 ; Veldman et al., 2009; AbdelGhani et al., 2010). In S. enterica serotype Hadar, bla TEM was found with $b / a_{\mathrm{AmpC}}$, this come in agreement with results obtained by disk diffusion at the presence of cloxacillin. In recent years, there have been increasing reports of Salmonella isolates that produce either an ESBL or a plasmid-mediated AmpC $\beta$-lactamase (Dunne et al., 2000; Bradford, 2001b; Menezes et al., 2010), while the coexistence of cephalosporinase and ESBL mechanisms in the same Salmonella strain has been rarely documented (Hanson et al., 2002); the acquisition of both an ESBL and an AmpC $\beta$-lactamase in our isolate is a significant concern. Some ESBLs and cephalosporinases producers clones have spread, causing major outbreaks, and a few have disseminated across regions or countries (Livermore, 2004; Bouallègue et al., 2005; Rankin et al., 2005).

Mating assays conducted on ESBL Egyptian human isolates allowed the transfer of ESBL phenotype to recipient $E$. coli BM21 in association with b/aTEM and/or blasHV genes and plasmids of $60 \mathrm{~kb}$. Transfer of cephalosporinase phenotype was observed in only one isolate in association with bla $a_{\mathrm{TEM}}$ and $b / a_{\mathrm{AmpC}}$ genes, and with plasmids of 64 and $3.2 \mathrm{~kb}$. The first plasmidic AmpC in non-typhoid Salmonella was discovered in Saudi Arabia in $S$. enteritidis on mega transferable plasmid (Gaillot et al., 1997) and since it has reported in many other studies (Villa et al., 2002; Kim et al., 2004). Resistance to ESCs was mediated by plasmids as proved by gene transfer. It was reported that plasmid mediated mechanisms have led to resistance to almost every class of clinically important antibiotics (Philippon et al., 2002; Li et al., 2007). bla TEM are so far the most widespread plasmid borne $\beta$-lactmases genes as demonstrated in human ESBL-producing Salmonella in Egypt. Transfer of resistance to cefoxitin was observed in only one isolate. Resistance to cefoxitin in isolates that do not produce AmpC cephalosporinases may be due to non-enzymatic mechanisms. In Gram negative bacteria, outer membrane permeability barrier and multidrug efflux pumps play synergistically an important role in intrinsic resistance of these bacteria ( $\mathrm{Li}$ and Nikaido, 2004). We have described ESBL and AmpC cephalosporinase in human isolates of non-typhoid Salmonella from Egypt. Their presence may be significant factor of therapeutic failures; therefore, a careful monitoring of their evolution is recommended.

\section{ACKNOWLEDGEMENTS}

The authors wish to thank all the contributing laboratories that provided isolates for this study. We are especially grateful to F. GACEM for her help. This work was supported by grant from National Fund for Research of Algeria and Ain Shams University (Egypt).

\section{REFERENCES}

AbdelGhani SM, Moland ES, Black JA, Hanson ND, Goering RV, Thomson KS, Amine MA, Saafan AE, Helal S, Gaafar, Younan M (2010). First report of CTX-M-14 -producing clinical isolates of Salmonella serovar Typhimurium from Egypt. J. Infect. Dev. Ctries., 4: 58-60.

Ambler RP (1980). The structure of $\beta$-lactamases. Philos. Trans. R. Soc. Lond. B 289: 321-331.

Arlet G, Barrett TJ, Butaye P, Cloeckaert A, Mulvey MR, White DG. (2006). Salmonella resistant to extended-spectrum cephalosporins: prevalence and epidemiology. Microbes Infect., 8: 1945-1954.

Bakour R, Laroche Y, Cornelis G (1983). Studies of the incompatibility and replication of the $70 \mathrm{~kb}$ virulence plasmids of Yersinia. Plasmid., 10: 279-289.

Banajeh SM, Ba-Oum NH, Al-Sanabani RM (2001). Bacterial aetiology and antimicrobial resistance of childhood diarrhoea in Yemen. J. Trop. Pediatr., 47: 301-303.

Bonnet R (2004). Growing group of extended-spectrum betalactamases. The CTX-M enzymes. Antimicrob Agents Chemoth., 48: 1-14.

Bouallègue GO, Salem YB, Fabre L, Demartin M, Grimont PAD, Mzoughi R, Weill FX (2005). Nosocomial Outbreak Caused by Salmonella enterica Serotype Livingstone Producing CTX-M-27 Extended-Spectrum $\beta$-Lactamase in a Neonatal Unit in Sousse, Tunisia. J. Clin. Microbiol., 43: 1037-1044.

Bouchillon SK, Johnson BM, Hoban DJ, Johnson JL, Dowzicky MJ, Wu DH, Visalli MA, Bradford PA (2004). Determining incidence of extended-spectrum B-lactamase producing Enterobacteriaceae, vancomycin-resistant Enterococcus faecium and Methicillin-resistant Staphylococcus aureus in 38 Centres from 17 countries: the PEARLS study 2001 - 2002. Int. J. Antimicrob. Agents., 24: 119-124.

Bradford P (2001a). Extended-spectrumb-lactamases in the 21st century: characterization, epidemiology, and detection of this important resistance threat. Clin. Microbiol. Rev., 14: 933-951.

Bradford $P$ (2001b). What's new in beta-lactamases? Current infectious Disease Reports., 3: 13-9.

Bush K, Jacoby GA, Medeiros AA (1995). A functional classification scheme for $\beta$-lactamases and its correlation with molecular structure. Antimicrob. Agents Chemother., 39: 1211-1233.

Bush K, Jacoby GA (2010). Updated Functional Classification of $\beta$ Lactamases. Antimicrob. Agents Chemother., 54: 969-976.

CA-SFM (Antibiogram Committee of French Society for Microbiology). Communiqué 2009; http//www.sfm.asso.fr/.

Chande C, Shrikhande S, Kapale S, Agrawal S, Fule RP (2002). Change in antimicrobial resistance pattern of Salmonella Typhi in central India. Indian. J. Med. Res., 115: 248-250.

Chen MH, Hwang WZ, Tsai SJ, Hsih YC, Chiou CS, Tsen HY (2010). Contamination of Salmonella Shwarzengrund cells in chicken meat from traditional marketplaces in Taiwan and comparison of their antibiograms with those of the human isolates. Poult. Sci., 89: 359365.

Chu C, Chiu CH (2006). Evolution of the virulence plasmids of nontyphoid Salmonella and its association with antimicrobial resistance. Microbes Infect., 8: 1931-1936.

Courvalin P, Goldstein F, Philippon A, Sirot J (1985). L'antibiogramme. $M P C$-Vidéom, Paris, 1 ère édition.

Decré D, Burghoffer B, Gautier V, Petit JC, Arlet G (2004). Outbreak of 
multi-resistant Klebsiella oxytoca involving strains with extendedspectrum $\beta$-lactamases and strains with extended spectrum activity of chromosomal $\beta$-lactamase. J. Antimicrob. Chemother., 54: 881-888.

Dunne EF, Fey PD, Kludt P, Reporter R, Mostashari F, Shillam P, Wicklund J, Miller C, Holland B, Stamey K, Barrett TJ, Rasheed JK, Tenover FC, Ribot EM, Angulo FJ (2000). Emergence of domestically acquired ceftriaxone-resistant Salmonella infections associated with AmpC beta-lactamase. J. Am. Med. Assoc., 284: 3151-3156.

Edelstein M, Pimkin M, Dmitrachenko T, Semenov V, Kozlova N, Gladin D, Baraniak A, Stratchounski L (2004). Multiple outbreaks of Nosocomial Salmonellosis in Russia and Belarus Caused by a single Clone of Salmonella enterica Serovar Typhimurium producing an extended-Spectrum B-Lactamase. Antimicrob. Agents Chemother., 48: 2808-2815

Fluit CA (2005). Towords more virulent and antibiotic-resistant Salmonella?. FEMS Imm. Med. Microb., 43: 1-11.

Gaillot O, Clement C, Simonet M, Philippon A (1997). A Novel transferable $\beta$-lactam resistance with cephalosporinase characteristics in Salmonella enteritidis. J. Antimicrob. Chemother., 39: 85-87.

Gebreyes WA, Altier C (2002). Molecular characterisation of multidrug resistant Salmonella enterica Subsp. Enterica Serovar Typhymurium isolates from swine. J. Clin. Microbiol., 40: 2813-2822.

Guerra B, Soto SM, Helmuth R, Mendoza MC (2002). Characterization of a self-transferable plasmid from Salmonella enterica serotype Typhimurium clinical isolates carrying two integron-borne gene cassettes together with virulence and drug resistance genes. Antimicrob. Agents Chemother., 46: 2977-2981.

Hanson ND, Moland ES, Hossain A, Neville SA, Gosbell IB, Thomson KS (2002). Unusual Salmonella enterica serotype Typhimurium isolate producing CMY-7, SHV-9 and OXA-30 $\beta$-lactamases. J. Antimicrob. Chemoth., 49: 1011-1014.

Hawkey PM, Jones AM (2009). The changing epidemiology of resistance. J. Antimicrob. Chemoth., 64: 3-10.

Hohmann EL (2001). Nontyphoidal salmonellosis. Clin. Infect. Dis., 32: 263-269.

labadene $\mathrm{H}$, Messai $\mathrm{Y}$, Ammari $\mathrm{H}$, Ramdani-Bouguessa N, Lounes $\mathrm{S}$, Bakour R, Arlet G (2008). Dissemination of ESBL and Qnr determinants in Enterobacter cloacae in Algeria. J. Antimicrob. Chemother., 62: 133-136.

labadene H, Messai Y, Ammari H, Alouache S, Verdet C, Bakour R, Arlet $G$ (2009). Prevalence of plasmid-mediated AmpC betalactamases among Enterobacteriaceae in Algiers hospitals. Int. J. Antimicrob. Agents., 34: 340-342.

Jarlier V, Nicolas M, Fornier G, Philippon A (1988). Extended broad spectrum $\beta$-lactamases conferring transferable resistance to newer $\beta$ lactam agents in Enterobacteriaceae: Prevalence and susceptibility patterns. Rev. Inf. Dis., 4: 143-149.

Kado Cl, Liu ST (1981). Rapid procedure for detection and isolation of large and small plasmids. J. Bacteriol., 145: 1365-1373.

Kim JY, Park JY, Song LW, Jeong SH, Yoo YA, Lee KY (2004). Bacteraemia due to Salmonella enterica Serotype Montevideo producing plasmid-mediated AmpC $\beta$-lactamase (DHA-1). Ann. Clin. Lab. Sci., 34: 214-217.

Li XZ, Nikaido H (2004). Efflux-mediated drug resistance in bacteria. Drugs, 64: 159-204.

Li XZ, Mehrotra M, Ghimire S, Adewoye L (2007). $\beta$-Lactam resistance and $\beta$-lactamases in bacteria of animal origin. Vet. Microbiol., 121: 197-214.

Livermore DM (2004). ESBLs: Global aspects and laboratory detection. SCIEH Weekly Report., 38: 3.

Martinez, JL, Baquero F (2002). Interactions among strategies associated with bacterial infection: pathogenicity, epidemicity, and antibiotic resistance. Clin. Microb. Rev., 15: 647-679.
Menezes GA, Khan MA, Harish BN, Parija SC, Goessens W, Vidyalakshmi K, Baliga S, Hays JP (2010). Molecular characterization of antimicrobial resistance in non-typhoidal Salmonella associated with systemic manifestations from India. J. Med. Microbiol., 59: 14771483.

Messai Y, Benhassine T, Naim M, Paul G, Bakour R (2006). Prevalence of B-Lactams resistance among Escherichia coli isolates from a hospital in Algiers. Rev. Esp. Quimoterap., 19: 144-151.

Messai Y, labadene H, Benhassine T, Alouache S, Tazir M, Gautier V, Arlet G, Bakour R (2008). Prevalence and characterization of extended-spectrum beta-lactamases in Klebsiella pneumoniae in Algiers hospitals (Algeria). Pathol. Biol., 56: 319-325.

Miriagou V, Roxana F, Coman G, Tzouvelekis LS (2002). ExpandedSpectrum Cephalosporin-Resistant Salmonella Strains in Romania. J. Clin. Microbiol., 40: 4334-4336.

Miriagou V, Tassios PT, Legakis NJ, Tzouvelekis LS (2004). Expandedspectrum cephalosporin resistance in non-typhoid Salmonella. Int. J. Antimicrob. Agents, 23: 547-555.

Poirel L, Cabanne L, Vahaboglu H, Nordmann P (2005). Genetic environnement and expression of the extended spectrum $\beta$ lactamase blapER. Gene in the Gram-negatives bacteria. Antimicrob. Agents Chemother., 49: 1708-1713.

Rahn K, De Grandis SA, Clarke RC, McEwen SA, Galán JE, Ginocchio C, Curtiss III R, Gyles CL (1992). Amplification of an invA gene sequence of Salmonella typhimurium by polymerase chain reaction as a specific method of detection of Salmonella. Mol. Cell Probes., 6: 271-279.

Rankin SC, Whichard JM, Joyce K, Stephens L, O'Shea K, Aceto H, Munro DS, Benson C (2005). Detection of a blaSHV ExtendedSpectrum $\beta$-Lactamase in Salmonella enterica Serovar Newport MDR-AmpC. J. Clin. Microbiol., 43: 5792-5793.

Philippon A, Arlet G, Jacoby GA (2002). Plasmid-determined AmpCtype $\beta$-lactamases. Antimicrob. Agents Chemother., 46: 1-11.

Pitout JD, Nordmann P, Laupland KB, Poirel L (2005). Emergence of Enterobacteriaceae producing extended-spectrum $\beta$-lactamases (ESBLs) in the community. J. Antimicrob. Chemother., 56: 52-59.

Veldman K, Dierikx C, van Essen-Zandbergen A, van Pelt W, Mevius D (2010). Characterization of multidrug-resistant, qnrB2-positive and extended-spectrum- $\beta$-lactamase-producing Salmonella Concord and Salmonella Senftenberg isolates. J. Antimicrob. Chemother., 65: 872 875.

Villa L, Mammina C, Mariagou V, Tzouvelski LS, Tassios PT, Nastasi A, Carrattoli A (2002). Multidrug and Broad-Spectrum cephalosporin Resistance among Salmonella enterica Serotype Enteritidis clinical isolates in south Italy. J. Clin. Microbiol., 40: 2662-2665.

Wilke MS, Lovering AL, Strynadka NCJ (2005). $\beta$-Lactam antibiotic resistance: a current structural perspective. Cur. Opin. Microbiol., 8: 525-533.

Winokur PL, Vonstein DL, Hoffman LJ, Uhlenhopp EK, Doern GV (2001). Evidence for transfer of CMY-2 AmpC $\beta$-lactamase plasmids between Escherichia coli and Salmonella isolates from food animals and humans. Antimicrob. Agents Chemother., 45: 2716-2722.

Yates CM, Brown DJ, Edwards GF, Amyes SG (2003). Detection of TEM-52 in Salmonella enteric serovar enteritidis isolated in Scotland. J. Antimicrob. Chemother., 53: 407-408.

Yates CM, Amyes SG (2005). Extended-spectrum $\beta$-lactamases in nontyphoid Salmonella spp. isolated in the UK are now a reality: why the late arrival? J. Antimicrob. Chemother., 56: 262-264. 